\title{
Special issue: Qualitative and quantitative methods in tourism research
}

\author{
Biagio Simonetti ${ }^{1,2}$. Fabrizio Antolini ${ }^{3}$. Rosella Castellano ${ }^{4} \cdot$ Michele Gallo ${ }^{5}$. \\ María Rosario González-Rodríguez ${ }^{6} \cdot$ Antonio Giusti $^{7} \cdot$ Pasquale Sarnacchiaro $^{4}$
}

Published online: 11 August 2020

(c) Springer Nature B.V. 2020

This special issue includes a selection of papers presented at the:

"III International Conference on Tourism Dynamics and Trends" joint meeting with "X SISTUR Scientific Meeting" hosted by the University of Sannio (Benevento, November 14-16, 2018) and co-organized by the University of Seville (Spain), the Akdeniz University (Turkey) and the SISTUR (Italian Society of Tourism Science).

The Conference has been organized to offer an overview of Qualitative and Quantitative Methods in Tourism Research, focusing on various of economic and social policies actors. To make it as useful and constructive as possible, the Conference was open to the participation of scholars from several disciplines, experts, development policies managers dealing with the Tourism.

The Conference generated a discussion forum in which specialists and researchers offered their vision about the advances and tendencies in the research in tourism, travel and hospitality area.

This special issue contains 21 papers, selected after double-blind peer reviews, that apply qualitative and quantitative methods to provide solutions for monitoring and managing tourism activities.

Specifically, the contribution of Petrei et al. and Benedetti et al. deal with the study of Cultural Tourism by analysing official sources also through economic data. The paper of Gallo et al. deepens the analysis of museum tourism, while other authors treat the analysis of tourism in different countries (Özdemir et al.; Álvarez-García et al.). In some paper are discussed the cooperation strategies for particular forms of tourism in Italy (Boccia et al.) and risks deriving from territorial problems that can negatively impact on tourism

Biagio Simonetti

simonetti@unisannio.it

1 University of Sannio, Benevento, Italy

2 WSB University in Gdansk, Gdańsk, Poland

3 University of Teramo, Teramo, Italy

4 University Unitelma-Sapienza, Rome, Italy

5 University of Naples - L'Orientale, Naples, Italy

6 University of Seville, Seville, Spain

7 University of Firenze, Florence, Italy 
(Rampone et al.; Özdemir et al.; Hoskova-Mayerova et al.); In different papers the issue of quantification and measurement of tourism components in Italy is addressed (Sarnacchiaro et al.; Antolini et al.), The use of new commercial and communication technologies is covered in numerous papers (Conversano et al.; González-Rodríguez et al.; Shafique et al.; Siciliano et al.; Kozłowski). The analysis of internal areas or small towns, which also illustrate real examples of Italian realities, is clearly discussed in the works of Giordano and Grassini et al.

The economic analysis of the tourism sector and infrastructures is clearly highlighted also with examples in different countries (Kozłowski et al., Rinaldi et al.).

We are sure that the interdisciplinary approach is the best way to understand and manage the complex system of tourism.

As guest editors, at the end of our work, we would like to thank the authors for submitting their articles and especially the reviewers who made this Special Issue possible with their careful reviews. Many thanks to the Quality and Quantity Journal for giving us the opportunity to publish this special issue.

Publisher's Note Springer Nature remains neutral with regard to jurisdictional claims in published maps and institutional affiliations. 